\title{
MICROBIOLOGICAL SURVEILLANCE OF AIR QUALITY IN OPERATION THEATRES - COMPARISON OF THE CONVENTIONAL SETTLE PLATE TECHNIQUES VS USE OF AN AIR SAMPLING DEVICE.
}

Dr. A. G. Prathab, Dr. C. Lalitha.

1. Professor, Department of Microbiology, MS Ramaiah Medical College and Teaching Hospital, Bangalore.

2. Assistant Professor, Department of Microbiology, MS Ramaiah Medical College and Teaching Hospital, Bangalore.

\section{CORRESPONDING AUTHOR}

Dr. A. G. Prathab, Professor,

Department of Microbiology,

MS Ramaiah Medical College. M.S.R Nagar, Bangalore,

E-mail: dragprathab.@yahoo.co.in,

Ph: 91-9845195014.

ABSTRACT: BACKGROUND: Air as a means of nosocomial transmission has always remained as a cause of concern for health care providers and especially personnel involved in infection control activities. Although there are no uniform consensus on either the standards for surveillance, methodology for monitoring or the levels of acceptable contamination, it still remains a fact that we need to have some criteria to monitor air quality in atleast the critical care areas like the operation theatres. METHODOLOGY: Air quality surveillance in the operation theatres was performed simultaneously using the settle plate technique and an air sampling device. A total of 9 operation theatres were subjected to 4 surveillance cycles with a minimum of 2 recordings in each theatre following standard protocols and accepted method used to calculate bioburden. RESULTS: A comparison was made between the two methods using the data available with 72 recordings. In the settle plate technique, the mean $\mathrm{cfu} / \mathrm{mm} 3$ was found to be 17.11 and $22 \mathrm{cfu} / \mathrm{mm} 3$ at less than $30 \mathrm{~cm}$ and at a point more than $30 \mathrm{cms}$ of the operating table where as the corresponding means using the air sampler was137.83 and $164.11 \mathrm{cfu} / \mathrm{mm} 3$ respectively which showed considerable statistical significance .CONCLUSION : The use of an air sampler would be more appropriate in monitoring the air quality in critical care areas ensuring a more stringent method of quality check without compromising on the the standard accepted norms and addressing the issue of patient safety with reference to infection prevention .

KEY WORDS: Air Quality, Operation theatres, Colony forming units, Settle plate method, Air sampling device, Infection prevention.

INTRODUCTION \& BACKGROUND: It is a well known fact that air contains bacterial and fungal cells either as small individual particles or larger clumps and aggregates that can settle and serve as important sources of infection and the hospital is an important indoor environment responsible for spread of airborne pathogens. (1-3)

In this context, it is worth recalling the statement made by Riley that "the enclosed atmosphere of the hospital building and its human occupants constitute an ecological unit" (4)

It is also worth recalling that the critical care areas within the hospital including the operation theatres, critical care units, blood banks, transplant units and the emergency rooms can act as areas where there are various influencing factors that can contribute to patient 
acquiring infection during the hospital visit. In fact, hospital acquired infections kill more patients every year than do AIDS, breast cancer or road traffic accidents put together. (5)

Among the hospital acquired infections, Postoperative infections constitute a third of all infections.(6).The air in the operation theatre environment is said to have a role in the causation of post-operative infections.(7).The resulting deep surgical infections may at times be complicated, difficult to treat ,may require reoperations and at times may even be life threatening.(8) Infection prevention measures that need to be practiced to avoid such situations therefore rests not only with the operating personnel but would also involve the entire infection control team and the role of the clinical microbiologist becomes critical in terms of monitoring air quality and giving inputs to the HICC and also the engineering and the technical support staff who help in maintaining the accepted standards in terms of air quality in the operation theatres. It is in fact estimated that a 13 fold reduction in airborne bacteria in the operating rooms would reduce wound contamination by around $50 \% \cdot(9,10)$

The complex hospital environment and the OT environment in particular therefore requires special attention to ensure a healthy indoor air quality and an efficient monitoring system in place to protect patients and health care workers against possible hospital acquired infections and occupational diseases.

The monitoring of bioaerosol contamination in critical care areas like operation theatres becomes even more important as it is subject to many variables which would influence the outcome in terms of air quality including mechanical ventilation, filtration, differential pressure control, directional airflow control, local exhaust ventilation and use of ultraviolet germicidal irradiation for disinfection etc; in addition to the usual problem of trafficking of personnel and deviation from accepted guidelines which would contribute to compromising on indoor air quality. A pioneering study by Charnley and colleagues showed that reduction of airborne contamination by improving OR ventilation drastically reduced the rates of post-operative infections.(15)

These issues bring into focus the need to monitor indoor quality of air by the use of sampling techniques although it still remains a fact that there are no specific regulatory requirements mandated by law to ensure adequate control of biocontamination in the so called "Clean rooms".

In fact a study by Freiberg and colleagues $(18,19)$ have proposed that sedimentation plates represent a technically easier method than air sampling and when correctly used is a more realistic indicator of airborne bacterial contamination near the operating table as air sampling captures small particles that might be removed by ventilation whereas sedimentation plates represent larger particles which resist removal and may pose a risk of an SSI.In fact tere are also opinions which suggest the use of using a combination of the settle plate and volumetric air sapling technique when surgical techniques or theatre dress are to be validated

There have also been recommendations that particle counting be used as a routine procedure instead of microbiological sampling for routine monitoring of air in OTs. However there have also been suggestions that there is no correlation between particle and bacterial counts in in conventionally ventilated OTs with HEPA filters, indicating that particles may not always be of microbial origin.

It is a fact that volumetric sampling produces quantitative data that are more readily conceptualized and seems more relevant to situations in which a pathogen is inhaled and has been used as a standard for rigorous studies. However settle plates are said to be more appropriate for settling organisms and such sampling can be performed without special 
equipment or expertise. Unfortunately there are few side by side surveys of air sampling using volumetric and settle plate methods.(25)

In this context, a study was carried out to conduct air quality monitoring in operation theatres using the conventional settle plate method and an air sampling device and also to compare the test results obtained using the two methods which are the common methods used in most hospitals for surveillance of air quality in operation theatres .

METHODOLOGY: The air quality surveillance in the operation theatres were performed simultaneously using both the conventional settle plate technique and an air sampling device as per standard protocols. A total of 9 operation theatres were subjected to 4 surveillance cycles with a minimum of 2 recordings in each of the theatres.

The study was carried out in the operation theatres of the hospital before the start of the scheduled surgeries and adequate care was taken to ensure that there was no trafficking in these areas while the sampling procedures were completed. The air flow system was kept on for a period of $1 \mathrm{hr}$ before the entire procedure was carried out.(16) Standard op erating procedures (SOP) were followed at the operation theatres to monitor the bacterial load by the settle plate method and the air sampling device.(11)

In the settle plate method of sampling, Blood agar plates were appropriately labeled with respect to the date, time and period of exposure and placed at different areas in the operating rooms with the lids open for a period of 30 minutes and later closed. The plates were similarly also used to sample the air using the air sampler at the same sites as was done for the settle plates. Both the sets of plates after the procedure were closed and incubated at 37 degrees Celsius for $24 \mathrm{hrs}$.

After incubation, the colonies on each plate were counted and recorded as the number of bacteria carrying particles settling over the area of the plate in a given period of time.

The level of bacterial contamination of air is usually expressed as the number of bacteria carrying particles per cubic millimeter or cubic feet. In studies concerned with airborne infections of man, the particles counted are those that carry bacteria capable of growth on blood agar during aerobic incubation for 24-48hrs at 37 degrees centigrade.(11)

The comparison between the air sampling technique and the settle-plate technique was determined and the number of microorganisms expressed as $\mathrm{cfu} / \mathrm{m} 3$ was estimated for the settle plate technique using Koch's sedimentation method according to Polish standard PN89/204088/08,according to which,

$\mathrm{Cfu} / \mathrm{m} 3=\mathrm{a} . \mathrm{x} 1000 / \mathrm{p}$ x.t.x 0.2 where

$\mathrm{a}=$ the number of colonies on the petri plate

$p=$ the surface measurement of the of the plate used

$\mathrm{t}=$ the time of exposure of the petriplate.(13)

For the interpretation of results using the air sampling device, the number of colonies on the agar plate were counted and the positive hole conversion table was used to record the corrected no. of colonies (Probable Statistical total) and then if the sampled volume of air is 500 liters. ie. Sampling for 300 secs, the cfu was calculated per cubic $\mathrm{mm}$ as Probable statistical total using the positive hole conversion table/0.5. (21) 
Descriptive statistics comprising of mean and standard deviation was used to describe the average number of cfu at two different locations within the ot.

Independent student's test was applied to compare the statistical significance in the differences of the mean cfu counts at the two different locations. Level of significance was fixed at $5 \%$.

\section{Picture - 1. Air -Filters - Operation theatres}

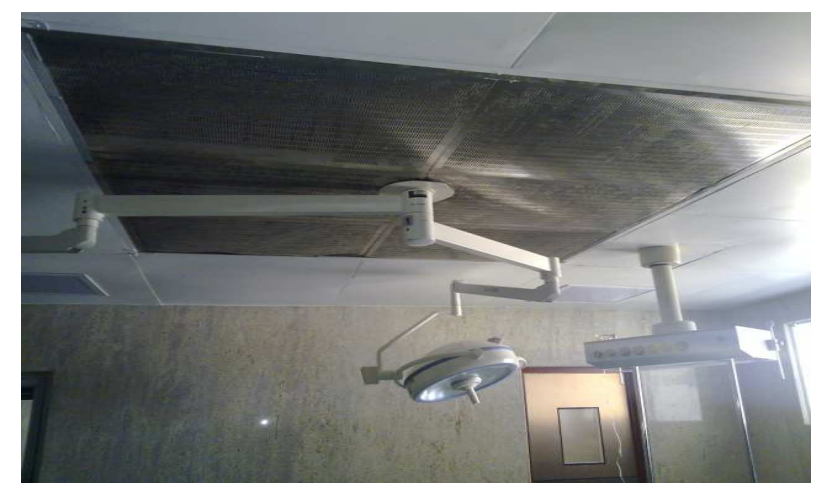

Picture - 2. Outlet - Duct

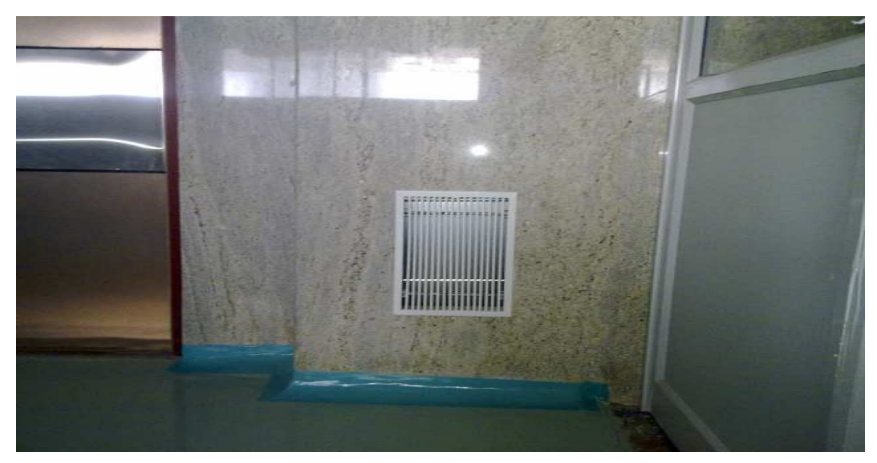

Pictures - 3 \& 4. Preparation of Culture plates - Settle plate \& Air sampling device.

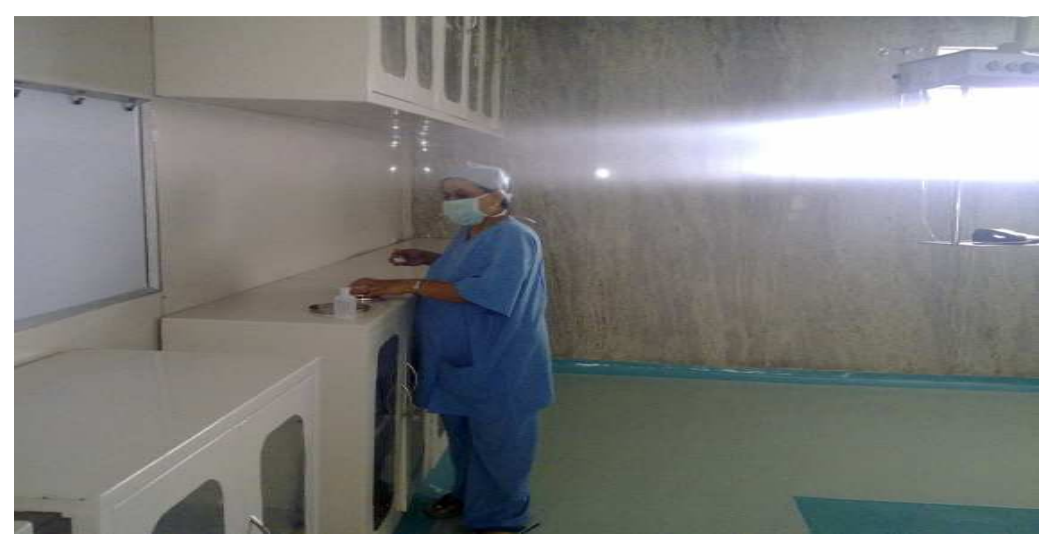

Journal of Evolution of Medical and Dental Sciences/Volume1/ Issue4/October - 2012 Page 374 


\section{ORIGINAL ARTICLE}

Pictures - 5. Air sampling using the device.

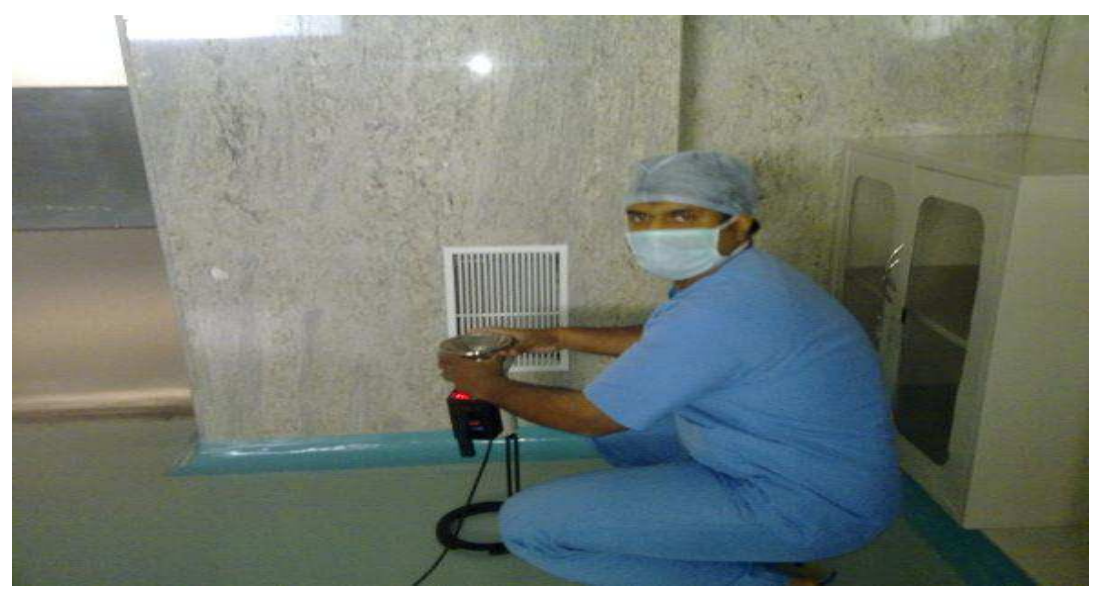

Pictures - 6. Air sampling using the device.

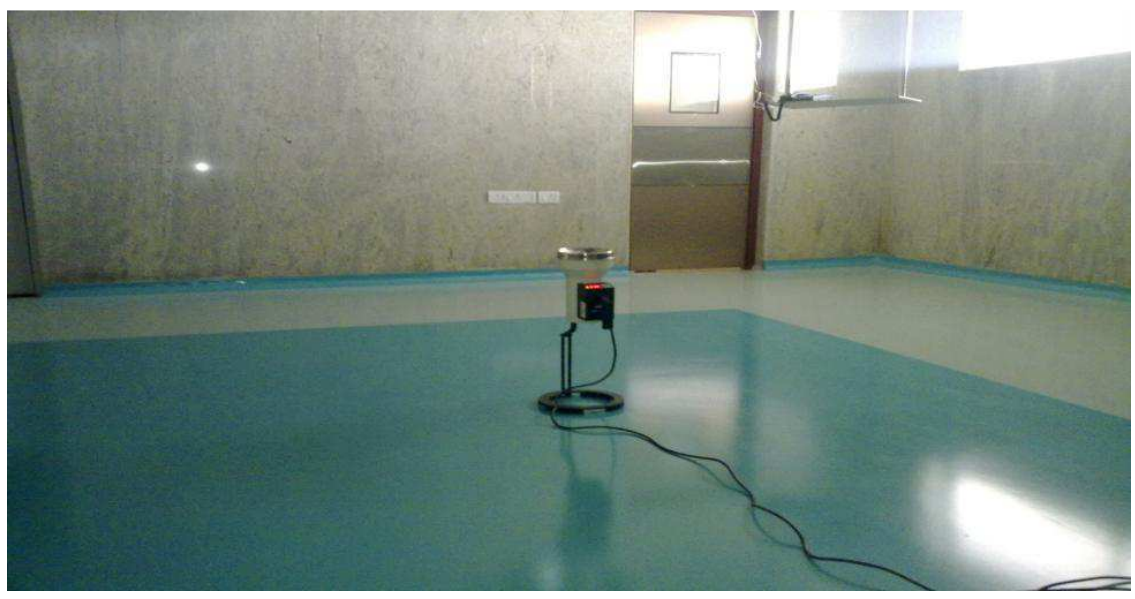

Picture : 7 - Air sampling device

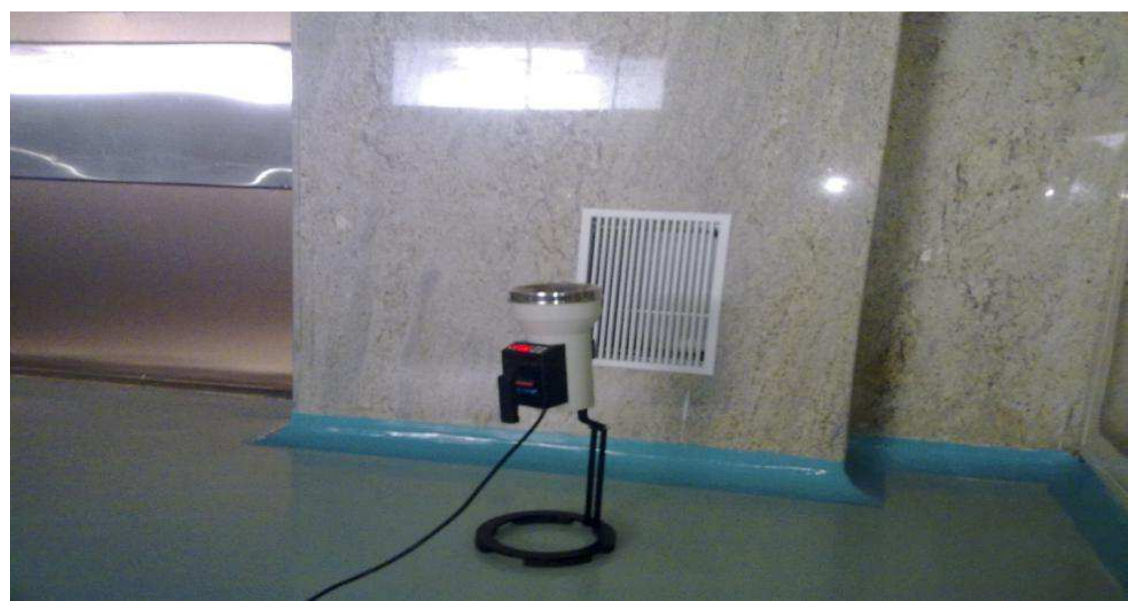

Journal of Evolution of Medical and Dental Sciences/Volume1/ Issue4/October - 2012 Page 375 
Picture :7 - Test - Results - Left : Settle plate technique.

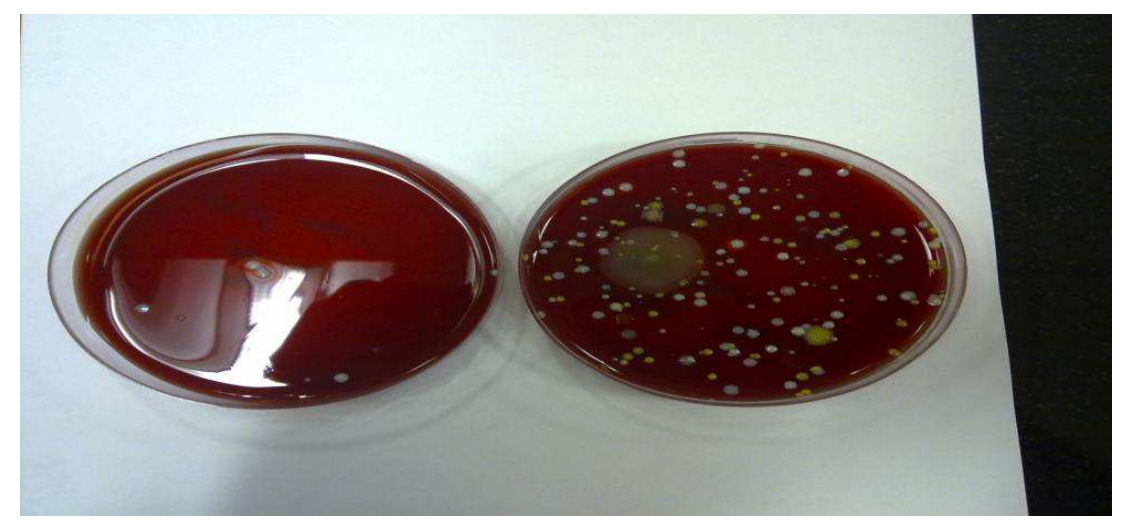

Table 1: Descriptive values of CFU count by different methods at two locations

\begin{tabular}{|c|c|c|c|c|}
\hline \multicolumn{5}{|c|}{ Group 1 (Allocation more than $30 \mathrm{cms}$ within the OT) } \\
\hline & $\begin{array}{c}\text { Minimu } \\
\mathrm{m}\end{array}$ & Maximum & Mean & $\begin{array}{c}\text { Std. } \\
\text { Deviation }\end{array}$ \\
\hline $\begin{array}{l}\text { Settle plate - No.of } \\
\text { colonies }\end{array}$ & 4 & 18 & 9.19 & 3.143 \\
\hline $\begin{array}{l}\text { Settle plate - Calculated } \\
\text { Cfu / mm3 }\end{array}$ & 7 & 33 & 17.11 & 5.845 \\
\hline $\begin{array}{l}\text { Air_sampler- No.of } \\
\text { colonies }\end{array}$ & 52 & 112 & 77.67 & 13.527 \\
\hline $\begin{array}{l}\text { Correction factor-No.of } \\
\text { colonies, based on Postive } \\
\text { Hole conversion table }\end{array}$ & 54 & 121 & 82.06 & 15.090 \\
\hline $\begin{array}{l}\text { Air_sampler- Calculated- } \\
\mathrm{Cfu} / \mathrm{mm} 3 \text { _ }\end{array}$ & 108 & 242 & 164.11 & 30.180 \\
\hline \multicolumn{5}{|c|}{ Group 2 (Allocation within $30 \mathrm{cms}$ of the OT table in the OT) } \\
\hline $\begin{array}{l}\text { Settle plate - No.of } \\
\text { colonies }\end{array}$ & 4 & 12 & 7.08 & 1.763 \\
\hline $\begin{array}{l}\text { Settle plate - Calculated } \\
\text { Cfu / mm3 }\end{array}$ & 7 & 22 & 13.11 & 3.370 \\
\hline $\begin{array}{l}\text { Air_sampler- No.of } \\
\text { colonies }\end{array}$ & 40 & 102 & 64.56 & 14.632 \\
\hline $\begin{array}{l}\text { Correction factor-No.of } \\
\text { colonies, based on Postive } \\
\text { Hole conversion table }\end{array}$ & 41 & 110 & 68.92 & 16.384 \\
\hline $\begin{array}{l}\text { Air_sampler- Calculated- } \\
\mathrm{Cfu} / \mathrm{mm} 3 \text { - }\end{array}$ & 82 & 220 & 137.83 & 32.767 \\
\hline
\end{tabular}

Journal of Evolution of Medical and Dental Sciences/Volume1/ Issue4/October - 2012 Page 376 
Table 2: Comparison of Mean Cfu counts using two different methods of surveillance of air quality :

\begin{tabular}{|l|r|r|r|}
\hline Group & \multicolumn{1}{|c|}{ Mean } & \multicolumn{1}{c|}{ Std. Deviation } & \multicolumn{1}{c|}{ Std. Error Mean } \\
\hline Settle Plate & 15.11 & 5.147 & .607 \\
\hline Air Sampler & 150.97 & 33.961 & 4.002 \\
\hline
\end{tabular}

From the above table it is observed that the mean CFU count using settle plate technique was 15.11 (5.14) where as the same using the Air sampling device was 150.97 (33.961). This difference in mean CFU count between the two techniques was found to be highly statistically significant $(\mathrm{P}<0.001)$

\begin{tabular}{|c|c|c|c|c|c|c|}
\hline & \multirow[t]{2}{*}{$\mathrm{N}$} & \multirow[t]{2}{*}{ Mean } & \multirow[t]{2}{*}{$\begin{array}{c}\text { Std. } \\
\text { Deviation }\end{array}$} & \multirow[t]{2}{*}{$\begin{array}{l}\text { Std. } \\
\text { Error }\end{array}$} & \multicolumn{2}{|c|}{$\begin{array}{c}\text { 95\% Confidence Interval for } \\
\text { Mean }\end{array}$} \\
\hline & & & & & $\begin{array}{l}\text { Lower } \\
\text { Bound }\end{array}$ & Upper Bound \\
\hline 1 & 36 & 17.11 & 5.845 & .974 & 15.13 & 19.09 \\
\hline 2 & 36 & 13.11 & 3.370 & .562 & 11.97 & 14.25 \\
\hline 3 & 36 & 164.11 & 30.180 & 5.030 & 153.90 & 174.32 \\
\hline 4 & 36 & 137.83 & 32.767 & 5.461 & 126.75 & 148.92 \\
\hline Total & 144 & 83.04 & 72.337 & 6.028 & 71.13 & 94.96 \\
\hline
\end{tabular}

From the above table the mean (SD) CFU is $\_72.337 \mathrm{cfu} / \mathrm{mm} 3$. Only the difference in the mean CFU count at less than $30 \mathrm{~cm}$ and more than $30 \mathrm{~cm}$ in the OT using settle plate was not found to be statistically significant with all the other mean values differeing significantly using Analysis of Variance (ANOVA) p $<0.05$.

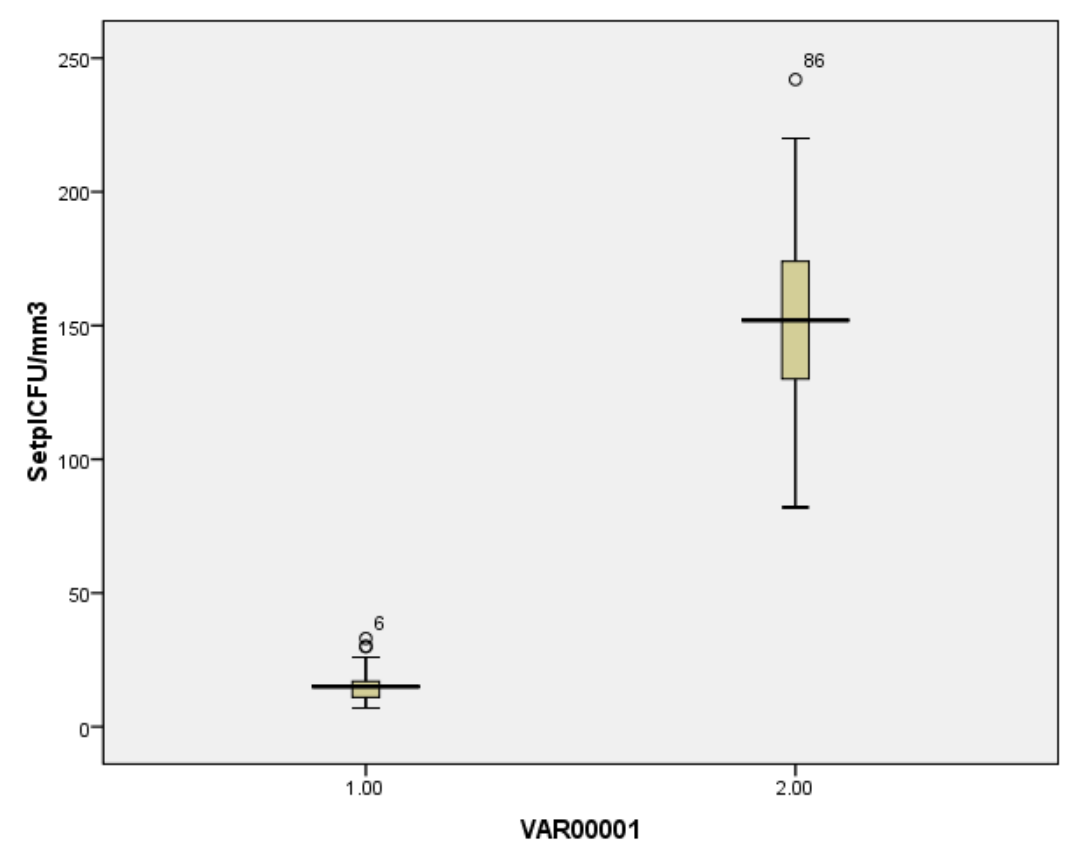

Journal of Evolution of Medical and Dental Sciences/Volume1/ Issue4/October - 2012 Page 377 


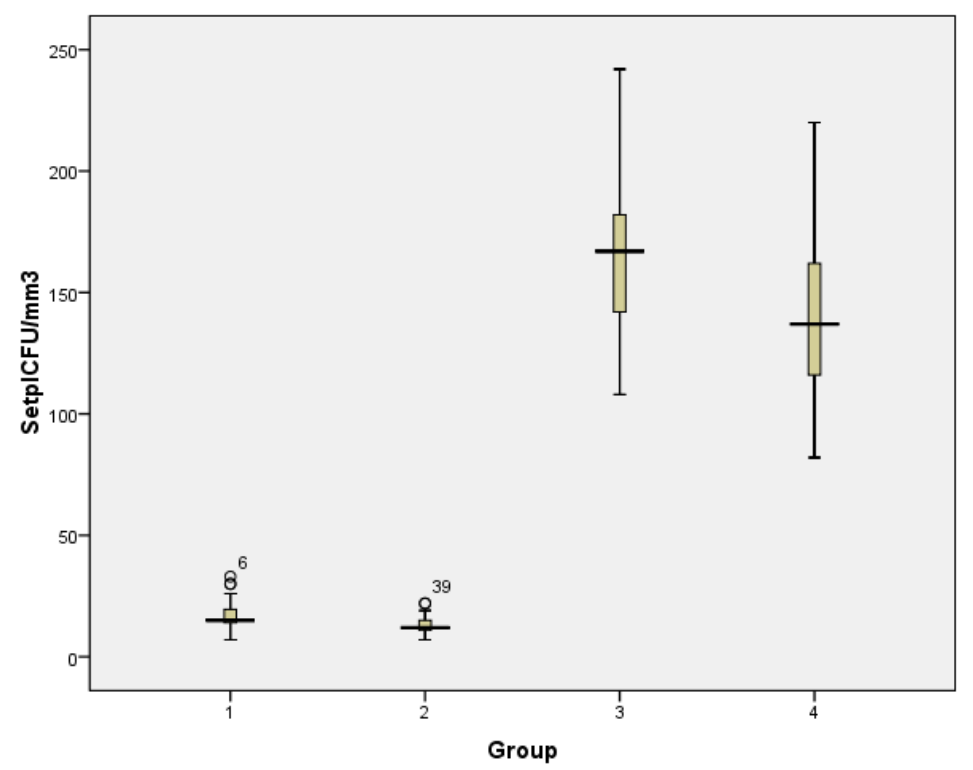

Groups :

1- Settle plate method at $>30 \mathrm{cms}$ in the OT

2- Settle plate method at $<30 \mathrm{cms}$ in the OT

3- Use of Air sampler at $>30 \mathrm{cms}$ in the OT

4- Use of Air Sampler at $<30 \mathrm{cms}$ in the OT

RESULTS AND DISCUSSION: Microbiological sampling of air in health care facilities remains a controversial issue because of currently unresolved technical limitations, concrete guidelines and policies and the need for substantial laboratory support. It has been a long debated issue that airborne sources of possible bacterial contamination of the environment in operation theatres can be potential threat for being an important cause in increasing the incidence of surgical site infections. This can contribute to the already existing burden of nosocomial infections in a health care set-up. The morbidity due to a surgical site infections and the additional health care costs can be taxing to the patients undergoing surgical procedures , and it is the responsibility of the clinical microbiologist as a part of the infection control team to reassure the operating surgeons and the engineering department in charge of maintenance of the ventilation systems installed in these areas that the air quality remains within the acceptable norms. Following redesign and construction of a new theatre-complex ,air quality surveillance in the operation theatres were performed simultaneously using both the conventional settle plate technique and an air sampling device as per standard protocols and the bioburden was calculated using accepted norms.

The study was undertaken to perform air quality surveillance of the operation theatres following redesign and construction of the new OT complex and to determine the level of bacterial contamination using two sampling techniques - one a conventional method of settle plate technique which is considered to be out dated but still used to perform surveillance in many hospitals.

It is important to realize that monitoring the quality of air in critical care areas especially the operation theatres where the surveillance process helps in maintaining accepted levels of air quality also is said to have an influence on reduction in surgical site infections and 
in turn on the rates of nosocomial infections prevalent in a health care set up. It helps in monitoring the capability of the air filters used in the OT's and also helps in assessing quality and making timely changes in measures that need to be adopted in order to maintain air quality in these areas.

The level of bacterial contamination of air is usually expressed as the number of bacteria carrying particles per cubic millimeter or cubic feet. In studies concerned with airborne infections of man, the particles counted are those that carry bacteria capable of growth on blood agar during aerobic incubation for 24-48hrs at 37 degrees centigrade.(11)

Although there are no rigid guidelines with respect to either the method or the level of air contamination in the operation rooms, it is generally accepted that the levels should be within $180 \mathrm{cfu} / \mathrm{m} 3$ using the air sampling device and $35 \mathrm{cfu} / \mathrm{m} 3$ for the settle plate method. $(14,15,20)$

In the present study, the comparison between the air sampling technique and the settleplate technique was determined and the number of microorganisms expressed as $\mathrm{cfu} / \mathrm{m} 3$.

Using the settle plate technique, it was estimated that the mean $\mathrm{cfu} / \mathrm{mm} 3$ was found to be 17.11 and $22 \mathrm{cfu} / \mathrm{mm} 3$ at less than $30 \mathrm{~cm}$ and at a point more than $30 \mathrm{cms}$ of the operating table in the operation theatre where as the corresponding means using the air sampler was137.83 and $164.11 \mathrm{cfu} / \mathrm{mm} 3$ respectively and was found to be highly statistically significant.

This shows the extent of difference in the test results using the two methods and conclusion in terms of certifying the areas as being microbiologically safe or within acceptable limits. The difference should be able to convince health care professionals, the personnel involved in maintenance of the filter systems and those dealing with the management and monitoring of Hospital infection control practices and policies and the authorities involved with infrastructure and hospital administration to definitely changeover to the current practice of monitoring air quality using the air sampling device rather than the traditional method of using settle-plates which still remains the practice in many health care centers.

Though settle plate method may be regarded as a crude measure of airborne contamination, in places without other facilities it can still provide a simple and cost effective way of enumerating the contamination rate of horizontal surfaces at multiple points. Although there is no need to routinely perform surveillance cultures in operation theatre's (22),there are evidences which suggest that there is a need to monitor the air quality which may help in reduction of post-operative complications due to infection. Air samplers allows sampling over a short time period comparatively and hence can indicate the occurrence of individual events like influx of excess personnel and unnecessarily opening the door. These events are lost while using settle plates since sampling is done for comparatively longer time periods. To date, there are no standardized methods available in the country for air sampling in operation theatres or for its frequency. . Routine bacteriological surveillance of operation theatres are nor advocated as results apply only to the moment and location they were obtained at $(10,8,17)$.

At present, there is no international consensus on the methods, types of samples

(settle plate versus, volumetric air sampling)frequencies of sampling and tolerable limits of bioburden in Operation theatres. However it is recommended by most infection control practitioners that rather than taking routine surveillance cultures, bacteriological sampling may be required in situations of commissioning of new operation theatres either after new constructions or after engineering modifications, for investigation of epidemics of surgical site or for validation of changes of either products used or procedures followed in maintenance of operation theatres in terms of cleaning, disinfection or ventilation and for purpose of education. 
It would also be useful to have a annual record of the airflows and the bacterial counts for each operating theatre which may be useful as a comparison in future.(24).

ACKNOWLEDGEMENT: Dr. Nandakumar, Associate Professor- Department of Community Medicine- For Statistical analysis of the study. E-mail-Id: bsnandakumar@gmail.com

\section{REFERENCES :}

1. 1.Riley,R.L.,1974.Airborne infection.Am.J.Med.,57:466-475

2. 2.Parker,M.T.,1973.Transmission in Hospital IV.International symp.Aerobiol.oostheck publ,co.utrecht,Netherlands:428-444

3. 3.C.,1970. Intramural spread of infection-airborne or not? Pro C.III Int,sympo Aerobiol.El.D.H.Silver Academic Press : 94-95

4. Riley,R.L.,1974.The ecology of indoor atmosphere airborne infection in hospital.J.Chronic Dis.,25:421-423

5. Childs, D. Hospital infection kills more than Cors,AIDS and Breast cancer.Available at:http://www.rense.general74/hosp.htm

6. Pench GL,Cheng AFB,Wang SL and Donnan S . Repeated prevalence surveys formonitoring effectiveness of hospital infection control. Lancet :1964:2:10211023.

7. Hart D. Pathogenic bacteria in air of operating rooms.Arch Surg:1938:37:4:521530.

8. Dharan, S ., Pittet, D. Environmental controls in operation theatres. J. Hosp Infect, 2002; 51: 79-84

9. 9.Whyte,W., Hambraeus, A., Laurell,G., Hoborn, J. The relative importance of routes and sources of wound contamination during general surgery. II . airborne . J. Hosp Infect, 1992; 22: 41-54.

10. Mangram, A.J., Horan, T.C., Pearson,M.L., et al. Guideline for prevention of surgical site infection,infection control and hospital epidemiology.Am.J Infect Conrol, 1999;27: 97-134

11. Charnley,J., Efthekhar,N. Post-operative infection in total prosthetic replacement arthroplasty of the hip joint.Br J Surg,1969;56:641-649.

12. Friberg,B., Friberg,S.,Burman,L.G.,Inconsistent correlation between aerobic bacterial surface and air counts in operating rooms with ultra clean laminar airflows: Proposal of new bacteriological standard for surface decontamination.J Hosp Infect, 1999;42:287-293.

13. Friberg,B., Friberg,S.,Burman,L.G., Correlation between surface and air counts of particles carrying aerobic bacteria in operating rooms with turbulent ventilation:an experimental study. J Hosp Infect, 1999;42:61-68.

14. Frank.S.Rhame., The inanimate environment,Text book of Hospital InfectionsJohn.V.Bennet,Philip.S.Brachman,..,Lippincot-Raven publishers, $4^{\text {th }}$ edn:302

15. Purva Mathur., Text book of Hospital acquired infections,prevention and control,Lippincott Williams \& Wilkins $1^{\text {st }}$ Edn;2010:256

16. Mehta G. Microbiological surveillance of operation theatre. availablefrom:http://www.orthoteers.org/(S(yp4gi4eh11f1mm45pyosvuio))/m ainpage.aspx? article $=372$

17. C. Pasquarella*, O. Pitzurra† and A. Savino* Journal of Hospital Infection (2000) 46: 241-256. 
18. Air petri sampling system - for monitoring the microbial quality of critical environments - Instruction catalogue, Himedia laboratories Private Limited.

19. ,

20. Parker MT. Hospital - acquired infections: Guidelines to laboratory methods, WHO Regional Publications, European Series No.4. (WHO Regional Office for Europe Copenhagen)1978,28.

21. Malathi Jambulingam ${ }^{1}$, Suresh Kumar Parameswaran ${ }^{2}$, Sagar Lysa ${ }^{2}$, Margarita Selvaraj ${ }^{1}$, Hajib N Madhavan ${ }^{1}$., A study on the incidence, microbiological analysis and investigations on the source of infection of postoperative infectious endophthalmitis in a tertiary care ophthalmic hospital: An 8-year study.,Indian Journal of Ophthalmology,2010:58:4:297-302

22. Design and maintenance of health care facilities -Manual of "Infection Control Procedures" - N.N.Damani, $2^{\text {nd }}$ edn.,p 17-24.

23. Prevention of surgical site infections -Manual of "Infection Control Procedures" N.N.Damani, $2^{\text {nd }}$ edn.,p 245-257.

24. Smyth,E.T,M.,Humphreys,H., Stacey,A.et al. Survey of operating theatre venlilation facilities for minimally invasive surgery in Great Britain and Northern Ireland: Current practices and considerations for the future.J Hosp Infect 2005;61:112-122

25. Design of wards and specialized units - Operation theatres, Manual of Hospital infection control-setting up a cost effective programme,Shaheen Mehtar,Oxford university press,1992, 139-140. 